\title{
Quantifying expression of Geobacter spp. oxidative stress genes in pure culture and during in situ uranium bioremediation
}

\author{
Paula J Mouser ${ }^{1}$, Dawn E Holmes ${ }^{1}$, Lorrie A Perpetua ${ }^{1}$, Raymond DiDonato ${ }^{1,3}$, \\ Brad Postier ${ }^{1,4}$, Anna Liu ${ }^{2}$ and Derek R Lovley ${ }^{1}$ \\ ${ }^{1}$ Department of Microbiology, University of Massachusetts, Amherst, MA, USA and ${ }^{2}$ Department \\ of Mathematics and Statistics, University of Massachusetts, Amherst, MA, USA
}

\begin{abstract}
As part of an effort to diagnose the physiological status of Geobacter species during in situ bioremediation of uranium-contaminated groundwater, transcript levels for two genes potentially associated with oxidative stress, $c y d A$ and $\operatorname{sodA}$, were quantified throughout a bioremediation field study in Rifle, CO, USA. Despite the accumulation of $\mathrm{Fe}(\mathrm{II})$ in the groundwater, which is inconsistent with the presence of dissolved oxygen, both genes were highly expressed during the bioremediation process. Therefore, the response to oxidative stress was further evaluated with Geobacter uraniireducens, an isolate from the Rifle site. When $G$. uraniireducens cultured with fumarate as the electron acceptor was exposed to $5 \%$ oxygen for $8 \mathrm{~h}$, there was a significant increase in cydA and sodA transcripts as well as other genes associated with oxygen respiration or oxidative stress. Oxygen-exposed cells had lower transcript abundance for genes associated with anaerobic respiration, metabolism and motility. Short-term oxygen exposure had little impact on cydA transcript levels, as more than $1 \mathrm{~h}$ was required for increases to levels comparable to the subsurface. Abundance of $c y d A$ and sodA transcripts for the isolate $G$. sulfurreducens were always higher in cells cultured with Fe(III) compared with fumarate as an electron acceptor, even when fumarategrown cells were exposed to oxygen, and Fe(III)-grown cells were grown anaerobically. These results suggest that the apparently high Geobacter cydA and sodA expression during bioremediation cannot necessarily be attributed to oxidative stress and demonstrate that diagnosis of the metabolic status of subsurface microorganisms through transcript analysis should be coupled with appropriate geochemical analyses.

The ISME Journal (2009) 3, 454-465; doi:10.1038/ismej.2008.126; published online 8 January 2009

Subject Category: integrated genomics and post-genomics approaches in microbial ecology

Keywords: oxygen; Geobacter, $\operatorname{cyd} A$; $\operatorname{sod} A$; bioremediation; groundwater
\end{abstract}

\section{Introduction}

In order to improve bioremediation strategies for contaminated subsurface environments, it is necessary to understand the physiological requirements of dominant bacteria at these sites, to monitor their metabolic condition in situ and to relate this metabolic state to factors controlling the rate and extent of bioremediation processes (Lovley, 2003).

Correspondence: PJ Mouser, Department of Microbiology, Sanborn, Head and Associates Inc., 95 High Street, Portland, ME 04101, USA.

E-mail: pjmouser@gmail.com

${ }^{3}$ Current address: BIOBASE Corporation, 100 Cummings Center, Suite 107A, Beverly, MA 01915, USA.

${ }^{4}$ Current address: Department of Biology, Washington University in St Louis, One Brookings Drive, Campus Box 1137, St Louis, MO 631410-4899, USA.

Received 2 September 2008; revised 24 November 2008; accepted 24 November 2008; published online 8 January 2009
The activity of soil microorganisms can be assessed using a number of different techniques (Lovley, 2003; Saleh-Lakha et al., 2005). Previous research in remediation applications has characterized physiological response by relating the number of key mRNA gene transcripts to metabolic rates (Chin et al., 2004; Holmes et al., 2005), iron availability (O’Neil et al., 2008), naphthalene concentrations (Fleming et al., 1993), dechlorination (Johnson et al., 2005; Lee et al., 2006; Rahm and Richardson, 2008) and limitations on fixed nitrogen (Holmes et al., 2004). Results from these studies have suggested that transcript levels for genes related to central metabolism or nutrient acquisition may be useful for monitoring the in situ metabolic state of key microorganisms during bioremediation. However, there are many other environmental conditions that are likely to influence the metabolic status of bacteria during bioremediation (Anderson and Lovley, 1997; Röling and Van Verseveld, 2002; 
Saleh-Lakha et al., 2005; Edwards et al., 2007). Most notably, the microbial response to a variety of environmental stresses must be understood and monitored (Hazen and Stahl, 2006).

One environmental stress likely to be encountered by bacteria in anaerobic zones of near-surface contaminated aquifers is exposure to oxygen. This may result from soil moisture infiltration, seasonal shifting of groundwater levels or perturbations during well sampling activities. Anaerobes are thought to be sensitive to intercellular oxygen because it inhibits key enzymes and reacts with biomolecules to produce more reactive radicals, such as superoxide $\left(\mathrm{O}_{2}^{\bullet}\right)$, hydrogen peroxide $\left(\mathrm{H}_{2} \mathrm{O}_{2}\right)$ and hydroxide $\left(\mathrm{HO}^{\circ}\right)$, that can damage or destroy nucleic acids, proteins and enzymes (Keyer and Imlay, 1996; Imlay, 2003). In addition, the introduction of oxygen to iron-reduced soils and groundwater has the potential to produce $\mathrm{HO}^{\bullet}$ in Fentontype reactions that may directly damage outer cellular membranes (Imlay, 2003). Microbial response to oxygen stress has been studied in a diversity of pure cultures. For example, Dehalococcoides sp. were found to be strict anaerobes (He et al., 2005), whereas Desulfovibrio spp., Shewanella spp. and Geobacter sulfurreducens are able to tolerate low oxygen concentrations or even grow under aerobic conditions (Moser and Nealson, 1996; Krekeler et al., 1998; Cypionka, 2000; Lin et al., 2004; Beliaev et al., 2005; Lobo et al., 2007). In bioremediation schemes that employ oxidative stress-sensitive species, such as bacteria that predominate during stimulated trichloroethylene (Ellis et al., 2000) or uranium bioremediation (Anderson et al., 2003), efficiency may be drastically reduced if the anaerobic bacteria are exposed to oxygen, resulting in increased biostimulation costs and remediation times. To date, limited research has been conducted on the specific response of Geobacter spp. to oxygen, and studies relating mRNA gene expression response to oxidative stress for other bacteria in subsurface environments remain few and difficult to decipher (Parro et al., 2007). This may be due to the fact that anaerobic bacteria have several different mechanisms for dealing with varying levels of intercellular oxygen (Mukhopadhyay et al., 2007).

The purpose of the study summarized here was to evaluate whether oxidative stress is an important factor influencing in situ bioremediation of uranium. Previous studies have demonstrated that Geobacter species are the primary microorganisms that respond to additions of acetate designed to stimulate in situ bioremediation of uraniumcontaminated groundwater, and they are involved in the reduction of U(VI) to U(IV) (Anderson et al., 2003; Istok et al., 2004; North et al., 2004; Holmes et al., 2005). Geobacter uraniireducens was isolated from uranium-contaminated subsurface sediments in Rifle, CO, USA, undergoing in situ uranium bioremediation (Shelobolina et al., 2008). The $16 \mathrm{~S}$
rRNA gene sequence for $G$. uraniireducens is an exact match to sequences that predominated in groundwater samples taken during field-scale bioremediation studies. Thus, this organism provides the opportunity to study the physiology of microorganisms likely to be involved in uranium bioremediation in the subsurface. The genome sequence of $G$. uraniireducens has recently been determined (www.jgi.doe.gov), and a search of this and other more intensively studied Geobacter genomes indicates that they possess genes with high similarities to genes found in other organisms that encode proteins that are known to be involved in an oxidative stress response (Methe et al., 2003). We report here that natural communities of $\mathrm{Geo}$ bacter species do express genes associated with oxidative stress, but as evidenced from pure culture studies, this is not a definitive indication that oxidative stress has a significant impact on in situ uranium bioremediation.

\section{Materials and methods}

Uranium bioremediation field study

In 2005, a small-scale in situ bioremediation experiment was conducted on the grounds of a former uranium ore-processing facility in Rifle, CO, USA, during the months of August and September. This site, designated Old Rifle, is part of the Uranium Mill Tailings Remedial Action (UMTRA) program of the US Department of Energy. The test plot was adjacent to a previously studied experimental plot (Anderson et al., 2003) with similar design but approximately one quarter the size. During the field experiment, an acetate-bromide solution (100:10 mM) mixed with site groundwater was injected into the subsurface to provide $\sim 10 \mathrm{mM}$ acetate as an electron donor to the groundwater over the course of 28 days as described earlier (Holmes et al., 2007).

Prior to sampling, the first $20 \mathrm{l}$ of groundwater was purged through dedicated monitoring well tubing connected to a peristaltic pump. After purge, samples were collected for geochemical analysis, then the pump tubing was connected to a pressurized filtration apparatus containing a series of two filters: a course $(1.2 \mu \mathrm{m})$ filter followed by a fine $(0.2 \mu \mathrm{m}) 263-\mathrm{mm}$ diameter Supor membrane disc filter (Pall Corporation, East Hills, NY, USA). Approximately $10 \mathrm{l}$ of groundwater was concentrated on filters at a rate of $1 \mathrm{lmin}^{-1}$, after which time filters were immediately removed, separately bagged into sterile whirl pak bags (Nasco, Fort Atkinson, WI, USA), flash frozen using an ethanoldry ice bath and stored at $-80{ }^{\circ} \mathrm{C}$ until extraction. Collection, preservation, and analysis of acetate and Fe(II) was conducted using ion chromatography and an $\mathrm{HCl}$ extractable ferrozine assay as described earlier (Lovley and Phillips, 1986; Anderson et al., 2003). 
Chemostat culture

G. uraniireducens RF4 (ATCC BAA-1134) was obtained from our laboratory culture collection and grown in continuous culture under anaerobic conditions with acetate $(5 \mathrm{~mm})$ as the electron donor and fumarate $(30 \mathrm{mM})$ as the electron acceptor at a dilution rate of $0.1 \mathrm{ml} \mathrm{min}^{-1}\left(0.03 \mathrm{~h}^{-1}\right)$. G. sulfurreducens PCA (DSM 12127) was obtained from our laboratory culture collection and grown continuously under anaerobic conditions with acetate $(5 \mathrm{mM})$ as the electron donor and either fumarate $(30 \mathrm{mM})$ or $\mathrm{Fe}(\mathrm{III})$ citrate $(50 \mathrm{mM})$ as the electron acceptor as described earlier (Esteve-Nunez et al., 2005). For both cultures, cells were grown in a bicarbonate-buffered medium (Lovley and Phillips, 1986) that was supplemented with a trace mineral and vitamin solution (Balch and Wolfe, 1979). Chemostat cultures of $G$. uraniireducens and G. sulfurreducens $(200 \mathrm{ml})$ were kept at a constant temperature of $30{ }^{\circ} \mathrm{C}$, stirred at 150 r.p.m., and the headspace was continuously gassed with a mixture of $\mathrm{N}_{2} / \mathrm{CO}_{2}(80: 20)$ at a rate of $50 \mathrm{ml} \mathrm{min}{ }^{-1}$. Steadystate conditions were maintained for four vessel volumes, and cells were either harvested, or stressed with oxygen by switching to a gas mixture containing $5 \%$ or $10 \%$ oxygen $\left(\mathrm{N}_{2} / \mathrm{CO}_{2} / \mathrm{O}_{2}, \quad 75: 20: 5\right.$ or 70:20:10) for a period of $8 \mathrm{~h}$.

\section{Batch culture}

Time course experiments with $G$. uraniireducens were conducted in batch culture with $15 \mathrm{mM}$ acetate as the electron donor and $40 \mathrm{mM}$ fumarate as the electron acceptor. Salts, mineral and vitamin solutions were added in the same concentrations described in continuous culture and cells were grown at a constant temperature of $30^{\circ} \mathrm{C}$. During oxidative stress, cultures were shaken horizontally at 150 r.p.m. to maximize the mixing of oxygen into media. Judging by the rapid and uniform change in color for cultures exposed to oxygen as compared with controls, we believe the mixing rate was sufficient for introducing oxygen into media from a headspace gas. Time course fumarate cultures were stressed with $10 \%$ headspace oxygen (vol/vol\%) during mid-log-phase growth. Cells were harvested at six different time points: just before stress $\left(T_{\mathrm{o}}\right)$, after $10 \mathrm{~min}, 30 \mathrm{~min}, 60 \mathrm{~min}, 6 \mathrm{~h}$ and $24 \mathrm{~h}$ of exposure. Headspace oxygen concentration was measured with a Hewlett-Packard series HP6890 gas chromatograph equipped with a thermal conductivity detector (Agilent Technologies Inc., Albany, NY, USA) and a Carboxen 1010 PLOT capillary column (Supelco, Bellefonte, PA, USA) with helium as a carrier gas as described earlier (Lin et al., 2004).

\section{RNA extraction}

Nucleic acids were extracted from groundwater filters using a modified phenol-chloroform extraction as described earlier (Holmes et al., 2004, 2005).
In brief, filters were crushed using liquid nitrogen, separated into eight 2-ml screw top tubes using a sterile RNAse-free spatula, and re-suspended in $800 \mu \mathrm{l}$ of TPE buffer $(100 \mathrm{mM}$ Tris-HCl, $100 \mathrm{mM}$ $\mathrm{KH}_{2} \mathrm{PO}_{4}$ and $10 \mathrm{mM}$ EDTA; $\mathrm{pH}$ 8.0). Cell cultures were harvested by transferring to pre-chilled $50-\mathrm{ml}$ conical tubes and centrifuging at 4000 r.p.m. for $15 \mathrm{~min}$ at $4{ }^{\circ} \mathrm{C}$. The supernatant was discarded and the pellet was flash-frozen in a liquid $\mathrm{N}_{2}$ bath and stored at $-80{ }^{\circ} \mathrm{C}$ until extraction. Pellets were resuspended in $4 \mathrm{ml}$ of TPE buffer, aliquoted into six separate 2-ml tubes, extracted as described above. The total RNA for groundwater samples and cell cultures were separated from other nucleic acids using the RNeasy RNA cleanup kit (Qiagen Corp., Valencia, CA, USA) and subsequently treated with DNA-free DNase (Ambion, Austin, TX, USA) according to the manufacturer's instructions. RNA quality was visualized on a $1 \%$ agarose gel electrophoresis, and the concentration and purity were quantified using a NanoDrop spectrophotometer (NanoDrop, Wilmington, DE, USA). All RNA samples were of high purity, with $260 / 280$ ratios of $1.8-$ 2.1. The absence of DNA contamination was verified by performing gene-specific PCR on all samples before RNA was subjected to reverse transcriptase with visualization of PCR products on a $2 \%$ agarose gel stained with ethidium bromide.

\section{Microarray analysis}

Total RNA $(0.5 \mu \mathrm{g})$ was amplified using the Bacterial MessageAmp II-Bacteria Prokaryotic RNA amplification kit (Ambion) according to the manufacturer's instructions. Microarray analysis was performed at the University of Massachusetts, Amherst Environmental Technology Center using Customarray $12 \mathrm{~K}$ microarray chips (Combimatrix, Mukilteo, WA, USA). Oligonucleotide probes were designed from the draft genome of $G$. uraniireducens (accession number NZ AAON00000000). A randomized block configuration was used as the statistical design, consisting of two experimental conditions: a control with anoxic ( $0 \%$ oxygen) growth versus a treatment with $5 \%$ oxygen stress. Each condition had three biological replicates and two technical replicates. The oligonucleotide array design, along with the raw and statistically treated results, is available on the NCBI Gene Expression Omnibus database (GSE12455).

The amplified RNA $(10 \mu \mathrm{g})$ was used to generate fluorescently labeled cDNA and hybridized to array slides as described earlier (Postier et al., 2008). Arrays were immediately scanned using a Genepix 4000B scanner (Molecular Devices Inc., Sunnyvale, CA, USA), analyzed using GenePix and Acuity 4.0 software, and exported for statistical analysis. Background effects during scanning were minimized by utilizing square outlines during spot finding. Data were preprocessed by subtracting the array background signal, calculated as the mean \pm 2 s.d. for the 
lowest $30 \%$ of negative controls within the array, from total spot intensity. Oligonucleotide probes with signals less than zero after adjusting to background intensity were omitted from further analysis. For the remaining data, the mean $\log _{2}$ ratio $\left[M=\log _{2}\right.$ (treatment/control)] was calculated, and differentially expressed genes were identified for biological and technical replicates using the linear model for microarray analysis (LIMMA) (Smyth and Speed, 2003; Smyth et al., 2005). Statistical significance was corrected for multiple comparisons. When multiple oligonucleotide probes were available for a given gene (this occurred for $99.4 \%$ of the genes), at least $50 \%$ of the probes needed to be statistically significant $(P<0.01)$ to be considered differentially expressed. Microarray results for three genes ( $c y d A$, sodA and proC) that represented positive and no significant difference in array expression ratios were confirmed using reverse transcription (RT)-PCR. $t$-test analysis between control and oxygen-exposed cells were conducted and tested for significant differences at an $\alpha=0.01$ level.

\section{Primer design and quantification of mRNA gene} transcripts

Gene-specific primers were designed for quantitative reverse transcription PCR (qRT)-PCR analysis from the $G$. uraniireducens and $G$. sulfurreducens genomes available on the DOE Joint Genome Institute website (www.jgi.doe.gov) using the Primer Express software (ABI). Optimal primer pairs were checked for dimers and hairpins using the NetPrimer software (PREMIER Biosoft, Palo Alto, CA, USA) and optimized using PCR gradient analysis. PCR products were cloned using the TOPO p2.1 kit (Invitrogen Corp., Carlsbad, CA, USA) and sequenced to verify gene specificity at the University of Massachusetts, Amherst Sequencing Facility. Table 1 shows the primers used to amplify $\sim 100$ 150-bp fragments of putative oxidative stress genes. In addition, two housekeeping genes that were not significantly up- or downregulated between oxygen exposed and control cells in the microarray experimental results, proC and $r p o B$, were used as controls in qRT-PCR analysis using the primer pairs shown in Table 1. Before qRT-PCR primers targeting $\operatorname{sod} A$, cyd $A$ and proC transcripts in the environment could be designed, it was necessary to construct cDNA with products amplified from the environment with degenerate PCR primer sets that targeted 400- to 800bp regions of each gene of interest. These degenerate primer sets were designed from gene alignments of available genomes, including $G$. metallireducens, G. sulfurreducens (Methe et al., 2003), strain FRC-32, Pelobacter carbinolicus and P. propionicus. Preliminary sequence data was obtained from the DOE Joint Genome Institute website (www.jgi.doe.gov). DNA sequences from at least 50 screened clones were used to design more specific qPCR primers for environmental quantification as described earlier (Holmes et al., 2005). All degenerate and quantitative RT-PCR primer pairs used for pure culture and environmental studies are outlined in Table 1. Sample cDNA was generated from mRNA transcripts using the DuraScript Enhanced Avian RT singlestrand synthesis kit (Sigma Aldrich) according to the manufacturer's instructions. Positive RT reactions were verified using PCR and visualized on a $2 \%$ agarose gel stained with ethidium bromide.

The number of mRNA transcripts was quantified using the Applied Biosystems 7500 Real-Time PCR system (PE Biosystems (Applied Biosystems), Foster City, CA, USA). Reactions (25 $\mu$ l total volume) consisted of $12.5 \mu \mathrm{l} 2 \times$ POWR SYBR green master mix (Applied Biosystems), $5 \mu \mathrm{l}$ of 1:10 diluted

Table 1 Forward and reverse primer pairs used for amplifying fragments from G. uraniireducens (Gura), G. sulfurreducens (Gsu), Geobacteraceae from the Rifle groundwater (Geo), and for quantifying Geobacteraceae with qRT-PCR (Geo qPCR)

\begin{tabular}{lll}
\hline Gene & Forward primer $5^{\prime}-3^{\prime}$ & Reverse primer $5^{\prime}-3^{\prime}$ \\
\hline Gura cydA $386 \mathrm{~F} / 489 \mathrm{R}$ & TGGTAGCCATCGCAACAAATC & CATCTCTGCCCTGCCGTTT \\
Gura macA $656 \mathrm{~F} / 758 \mathrm{R}$ & GCTCTGCCTGTCACAACGGT & CCGAGGTCTTCCGTGGGT \\
Gura sodA $141 \mathrm{~F} / 248 \mathrm{R}$ & GAAAGAGGATAAGACCGCCACA & CCCCCGAGTTTCAAAATAGT \\
Gura rbr $346 \mathrm{~F} / 465 \mathrm{R}$ & ATCGCCGCTGTTTCACG & CCAGACCACAGGCGCTTC \\
Gura proC $263 \mathrm{~F} / 367 \mathrm{R}$ & TCCTGCTCGTGAACCTCTCC \\
Gura rpoB 3201F/3308R & CGACGATCTTCCTCCTGGTG & TGTCTGTTCTCCGATCACCT \\
Gsu cydA $610 \mathrm{~F} / 710 \mathrm{R}$ & CTGCTCAGGAAGAACCGTATCG & ACCGTCACGTCCCGTGT \\
Gsu sodA $311 \mathrm{~F} / 425 \mathrm{R}$ & ATGAGGCGTGGGAGAAGGAT & TGCTCGTTGACCCAGAAGTTAA \\
Gsu Rub $885 \mathrm{~F} / 993 \mathrm{R}$ & GAGCGTCGCCATCAAGGA & CCGCAGGTGGGTCAAGAA \\
Gsu Rbr $377 \mathrm{~F} / 494 \mathrm{R}$ & CGGAAAAGCAGCACGAGAA & GTGTGGAGGTAGCCGCAGTT \\
Gsu proC $412 \mathrm{~F} / 494 \mathrm{R}$ & Holmes et al. $(2008)$ & \\
Geo sodA $200 \mathrm{~F} / 550 \mathrm{R}$ & TGGGARTTTAACGGCATGCG & TCGGCRGCCTTCCAGTCGAT \\
Geo cydA $80 \mathrm{~F} / 590 \mathrm{R}$ & TCATYTTCGTGCCSCTCACC & ATCACRAAGAARGCCGCCAC \\
Geo proC $75 \mathrm{~F} / 471 \mathrm{R}$ & ATWGGIGGIGGIAATATGGC & TCCCCACCAGGTCGAACA \\
Geo qPCR sodA $139 \mathrm{~F} / 270 \mathrm{R}$ & TGCTCGTTGATCCAGAAGTTGA & CCAGGATTTCGGCAGCTTC \\
Geo qPCR cydA $277 \mathrm{~F} / 424 \mathrm{R}$ & GGGTGCATCTTCTTTCCATCTG & ACCACCGCCATGAAATCG \\
Geo qPCR proC $156 \mathrm{~F} / 287 \mathrm{R}$ & TTGCGAAATGAGCGACACC & ATCGCGGCACTTTTCACG \\
\hline
\end{tabular}

Abbreviation: qRT-PCR, quantitative reverse transcription-PCR. 
template cDNA and 200 pmol of the appropriate primer pair. The thermal cycling parameters consisted of an activation step of $50^{\circ} \mathrm{C}$ for $2 \mathrm{~min}$, a denaturation step of $95{ }^{\circ} \mathrm{C}$ for $10 \mathrm{~min}$, followed by 45 cycles at $95{ }^{\circ} \mathrm{C}$ for $15 \mathrm{~s}$ and $60-66{ }^{\circ} \mathrm{C}$ for $1 \mathrm{~min}$. A standard curve and two types of negative controls were run concurrent with cDNA samples. Standard curves covered a range of approximately eight orders of magnitude (between $10^{1}$ and $10^{9}$ ), and were constructed as described earlier (Holmes et al., 2004). The first negative controls contained RNA template from each sample that had not been subjected to RT, and the second controls contained reaction solution without template. Real-time PCR product size and amplification were verified on a $2 \%$ agarose gel stained with ethidium bromide.

\section{Results and discussion}

Expression of putative oxygen stress genes during in situ uranium bioremediation

The genes $\operatorname{sod} A$ and $c y d A$ are highly conserved in the genome sequences of Geobacter species and, based on homology to characterized proteins in Desulfovibrio, Moorella and Shewanella species are predicted to be involved in oxidative stress responses (Methe et al., 2003; Heidelberg et al., 2004; Das et al., 2005; Machado et al., 2006). Therefore, transcript levels for these genes were quantified using primers designed to amplify the $\operatorname{sod} A$ and cydA sequences of the Geobacter species that predominated during in situ uranium bioremediation at the field study site in Rifle. During the first 2 days of acetate injection, the number of $\operatorname{sod} A, \operatorname{cyd} A$ and pro $C$ mRNA transcripts were not detected or approaching the detection limit of the RT-PCR system (approximately 100 molecules for $\operatorname{sod} A$ and proC transcripts, and 500 molecules for $c y d A$ transcripts) (Figure 1). As acetate concentrations increased in the groundwater following the initia- tion of acetate injection, transcript levels for $\operatorname{sod} A$ and $c y d A$, normalized to transcript levels of the housekeeping gene, proC, also increased (Figures 1a and $b$ ).

Transcript levels for sodA and $c y d A$ remained 1-3 orders of magnitude higher than proC transcripts during the stimulation experiment, then began to decrease as amendments were discontinued and acetate concentrations declined. Geobacteraceae $\operatorname{sod} A$ and $\operatorname{cyd} A$ transcripts were recovered despite the fact that considerable $\mathrm{Fe}$ (II) was detected throughout the experiment, indicating the presence of an anaerobic environment (Figure 1a). Although both the $\operatorname{sod} A$ and $c y d A$ gene expression patterns followed the same general trend with respect to acetate fluctuations, levels of transcripts were not significantly correlated with each other $\left(R^{2}=0.45\right)$. The in situ trends are consistent with batch growth trends of Geobacter species grown in uraniumcontaminated sediments with acetate amendment, where the number of organisms and their metabolic processes increase to some plateau level, representing a quasi-steady state, and begin to drop off as amendment resources are depleted (Finneran et al., 2002).

Gene expression patterns in G. uraniireducens in response to oxidative stress

To further interpret the results obtained from field studies, the transcriptional response of $G$. uraniireducens to oxygen stress was investigated using whole-genome DNA microarray comparisons. Transcript abundance of steady-state chemostat cultures grown with acetate as the electron donor $(5 \mathrm{mM})$ and fumarate as the electron acceptor $(30 \mathrm{~mm})$ was compared with transcript abundance in chemostat cultures grown under the same conditions, but exposed to $5 \%$ oxygen for $8 \mathrm{~h}$. Exposure to oxygen resulted in differential expression of 469 genes, 270 upregulated and 199 downregulated (Supplementary Table).
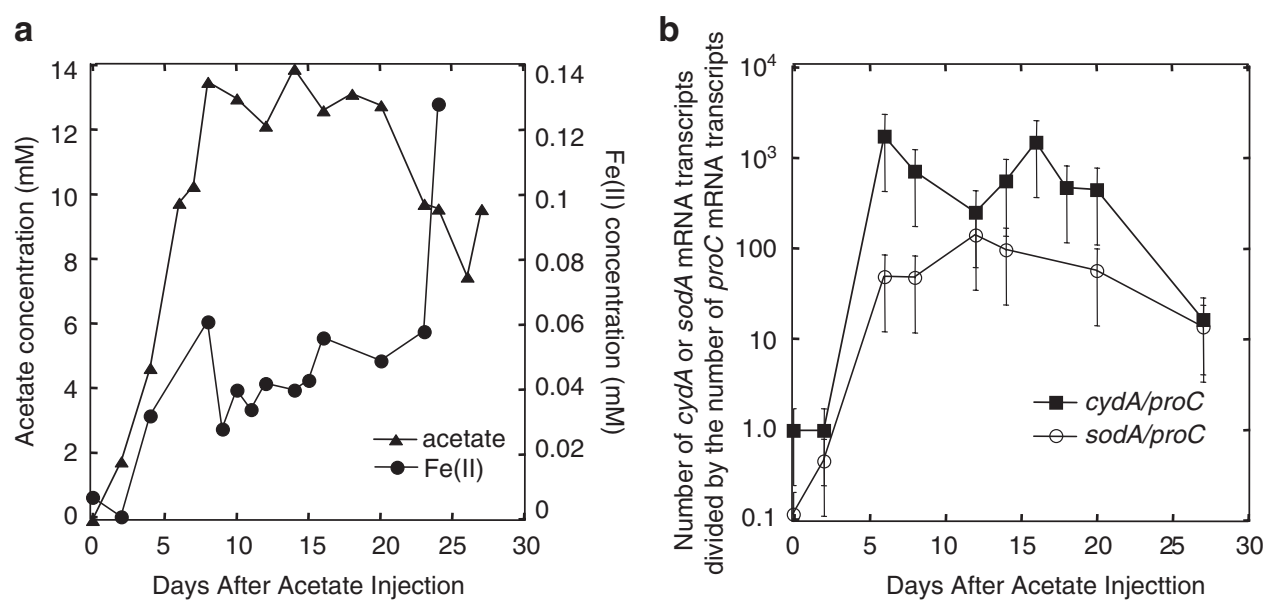

Figure 1 (a) Acetate and Fe(II) concentrations in groundwater during biostimulation of a uranium-contaminated aquifer and (b) the number of $c y d A$ and $\operatorname{sod} A$ mRNA gene transcripts relative to the number of proC transcripts expressed in situ by Geobacteraceae. 
Genes encoding proteins involved in energy metabolism and electron transport had the largest increases in transcript abundance when cells were exposed to oxygen. These included cytochrome $b d$ type quinol oxidases $c y d A$ and $c y d B$, and the cytochrome $C$ peroxidase $(m a c A)$ (Table 2). Other significantly upregulated genes included $\mathrm{Mn}-\mathrm{Fe}$ superoxide dismutase $(\operatorname{sod} A)$, desulfoferrodoxin $\left(d f_{x}\right)$, rubredoxin (rub) and rubrerythrin (rbr) (Table 2). The proteins encoded by these genes are thought to be involved in radical detoxification using superoxide dismutase and superoxide reductase systems (Brumlik and Voordouw, 1989; Voordouw and Voordouw, 1998; Jenney et al., 1999; Silva et al., 1999; Kurtz, 2006).

To further evaluate the expression patterns from the three genes that were monitored in the field studies, and to confirm microarray studies, qRT-PCR was used to quantify $\operatorname{cydA}$, sodA and proC transcripts. In accordance with the microarray results, $C y d A$ transcripts were 23 -fold higher in cells exposed to oxygen and $\operatorname{sod} A$ transcripts were

Table 2 Genes involved in energy production and metabolism that were differentially expressed $(P>0.01)$ in a microarray analysis for G. uraniireducens exposed to $5 \%$ oxygen

\begin{tabular}{|c|c|c|c|c|}
\hline Gene ID & Annotation & Mean $\log _{2}$ & Fold change & Gene name \\
\hline Gura2162 & Cytochrome $d$ ubiquinol oxidase, subunit II & 3.39 & 10.50 & $c y d B$ \\
\hline Gura1316 & Cytochrome $c 551$ peroxidase, 2 heme-binding sites & 3.18 & 9.03 & macA \\
\hline Gura2163 & Cytochrome $d$ ubiquinol oxidase, subunit I & 3.01 & 8.04 & cydA \\
\hline Gura2514 & Cytochrome $c$ biogenesis protein, CcmF/CcyK/CcsA family & 2.49 & 5.60 & - \\
\hline Gura0429 & $4 \mathrm{Fe}-4 \mathrm{~S}$ ferredoxin, iron-sulfur-binding domain protein & 2.27 & 4.82 & - \\
\hline Gura2379 & Cytochrome $b / b 6$ complex, iron-sulfur subunit & 2.24 & 4.71 & - \\
\hline Gura2207 & Desulfoferrodoxin ferrous iron-binding domain & 2.00 & 4.01 & $d f_{X}$ \\
\hline Gura1837 & Cytochrome $c$ family protein, 7 heme-binding sites & 1.89 & 3.69 & - \\
\hline Gura2513 & Desulfoferrodoxin & 1.88 & 3.67 & - \\
\hline Gura2004 & Cytochrome $c$ family protein, 6 heme-binding sites & 1.68 & 3.21 & omcT \\
\hline Gura1364 & Iron-sulfur-oxygen hybrid cluster protein (prismane) & 1.62 & 3.06 & hcp \\
\hline Gura3909 & Cytochrome $c, 3$ heme-binding sites & 1.44 & 2.72 & - \\
\hline Gura1453 & Manganese and iron superoxide dismutase & 1.41 & 2.65 & $\operatorname{sod} A$ \\
\hline Gura1838 & Cytochrome $c, 5$ heme-binding sites & 1.30 & 2.47 & - \\
\hline Gura0864 & Oxidoreductase, membrane subunit & 1.22 & 2.33 & - \\
\hline Gura0869 & Rubredoxin & 1.14 & 2.21 & rub \\
\hline Gura2789 & D-Isomer-specific 2-hydroxyacid dehydrogenase, NAD binding & 1.12 & 2.18 & $\operatorname{ser} A$ \\
\hline Gura1344 & Nitroreductase 3 family protein & 1.09 & 2.12 & - \\
\hline Gura4153 & Rubrerythrin & 1.05 & 2.08 & $r b r$ \\
\hline Gura0326 & NADH dehydrogenase I, G subunit & 1.05 & 2.07 & nuoG \\
\hline Gura0863 & Oxidoreductase, iron-sulfur cluster-binding subunit & 1.04 & 2.06 & - \\
\hline Gura0363 & Thioredoxin & 0.93 & 1.90 & - \\
\hline Gura0331 & Cytochrome $c, 1$ heme-binding site & 0.93 & 1.90 & - \\
\hline Gura3749 & Pyridine nucleotide-disulphide oxidoreductase dimerization region & 0.71 & 1.63 & - \\
\hline Gura2277 & Rubrerythrin & 0.63 & 1.55 & - \\
\hline Gura3554 & Electron transfer flavoprotein, Etf beta-subunit/FixA family & -0.63 & -1.55 & - \\
\hline Gura3652 & Cytochrome $c$ family protein, 5 heme-binding sites & -0.67 & -1.59 & - \\
\hline Gura3997 & Cytochrome $c, 6$ heme-binding sites & -0.70 & -1.63 & omcQ \\
\hline Gura0989 & Cytochrome $c$ family protein, 9 heme-binding sites & -0.71 & -1.63 & - \\
\hline Gura4232 & NADH dehydrogenase I, M subunit & -0.74 & -1.67 & пиом \\
\hline Gura3257 & Fumarate reductase, cytochrome $b$ subunit, putative & -0.74 & -1.67 & - \\
\hline Gura4238 & NADH dehydrogenase I, G subunit, putative & -0.75 & -1.68 & - \\
\hline Gura0621 & Cytochrome $c, 3$ heme-binding sites & -0.77 & -1.71 & - \\
\hline Gura3639 & Molybdopterin oxidoreductase & -0.80 & -1.74 & - \\
\hline Gura4233 & NADH dehydrogenase I, L subunit & -0.82 & -1.76 & nuoL \\
\hline Gura4243 & NADH dehydrogenase I, B subunit & -0.84 & -1.79 & - \\
\hline Gura4231 & NADH dehydrogenase I, N subunit & -0.84 & -1.79 & nuoN \\
\hline Gura2822 & Cytochrome $c, 12$ heme-binding sites & -0.84 & -1.79 & - \\
\hline Gura4236 & NADH dehydrogenase I, I subunit & -0.85 & -1.80 & nuoI \\
\hline Gura4242 & NADH dehydrogenase I, C subunit & -0.88 & -1.84 & nuoC \\
\hline Gura3996 & Cytochrome $c, 6$ heme-binding sites & -0.89 & -1.85 & - \\
\hline Gura3555 & $4 \mathrm{Fe}-4 \mathrm{~S}$ ferredoxin, iron-sulfur-binding domain protein & -0.89 & -1.85 & - \\
\hline Gura4241 & NADH dehydrogenase I, D subunit & -0.92 & -1.89 & - \\
\hline Gura4237 & NADH dehydrogenase I, H subunit & -0.96 & -1.94 & nuoH \\
\hline Gura0500 & Cytochrome $c$ family protein, 16 heme binding sites & -0.96 & -1.95 & - \\
\hline Gura4234 & NADH dehydrogenase I, K subunit & -1.03 & -2.04 & nuoK \\
\hline Gura4240 & NADH dehydrogenase I, E subunit & -1.07 & -2.09 & nuoE \\
\hline Gura0573 & Cytochrome $c, 29$ heme-binding sites & -1.13 & -2.18 & - \\
\hline Gura4239 & NADH dehydrogenase I, F subunit & -1.27 & -2.42 & nuoF \\
\hline Gura0497 & Cytochrome $c, 23$ heme-binding sites & -1.60 & -3.03 & - \\
\hline Gura0498 & Cytochrome $c, 24$ heme-binding sites & -1.88 & -3.68 & - \\
\hline
\end{tabular}


2.7-fold higher. These differences were statistically significant ( $t$-test, $P<0.01)$. In contrast, transcripts for proC were not statistically different between treatments $(P=0.11)$; the number of proC transcripts in oxygen-exposed cells was only 1.1-fold more abundant.

Genes that were most significantly downregulated were also involved in energy production and metabolism, and encoded nine NADH dehydrogenase (nuoE-nuoM) and $10 \mathrm{C}$-type cytochrome family proteins (Table 2). Similar changes in expression patterns have been observed in other bacteria upon changes in redox or energy condition. For example, fumarate reductase and NADH dehydrogenases were downregulated in Shewanella oneidensis when the redox potential of the terminal electron acceptor was increased (Beliaev et al., 2005). In Geobacter sulfurreducens, downregulation of several different metabolism genes, including $c$-type cytochromes and a $\mathrm{NADH}$ dehydrogenase, was observed in nitrogenfixing cells as opposed to cells grown in the presence of ammonium (Methe et al., 2005). Furthermore, studies with $E$. coli indicated that NADH dehydrogenases were inactivated in the presence of $\mathrm{H}_{2} \mathrm{O}_{2}$ to limit reactivity with NADH-metal reductants and the production of intercellular radicals (Imlay and Linn, 1988). G. uraniireducens demonstrated significant downregulation of genes encoding proteins involved in the formation of pili and flagella as well as chemotaxis sensory regulators under conditions of oxidative stress (Table 3). Evaluation of transcript levels from the gene encoding the pilus assembly protein, PilO with quantitative RT-PCR indicated that transcript levels were more than three-fold lower in oxygen-exposed cells ( $t$-test, $P<0.01$ ), consistent with the microarray results. Although cells grown anaerobically had flagella and numerous pili (Figures 2a and b), the number of pili was greatly diminished and flagella were not observed in cells exposed to oxygen (Figures 2c and d). Differential expression of motility and chemotaxis proteins in response to changes in redox conditions, and observations of aerotactic responses upon oxygen exposure have previously been described for facul- tative iron reducers (Beliaev et al., 2005) and sulfatereducing bacteria (Krekeler et al., 1998; Cypionka, 2000; Fareleira et al., 2003; Mukhopadhyay et al., 2007). In the case of $G$. uraniireducens, downregulation of motility proteins and observations of reduced pili and flagella suggest that shedding of motility functions may be a stress response mechanism and mode of energy conservation during exposure to oxygen.

\section{Time required for increase in transcript abundance} following oxygen exposure

A possible explanation for the detection of relatively high proportions of $\operatorname{sod} A$ and $\operatorname{cyd} A$ transcripts during in situ uranium bioremediation was that the cells being sampled were exposed to oxygen during the sampling procedure. It is possible that cells were exposed to trace amounts of oxygen diffusing into anaerobic groundwater during the short period of filtration $(\sim 10 \mathrm{~min})$, or to atmospheric oxygen levels just after filtration when the filter was removed from the filtration apparatus, placed in sterile bags and flash frozen in an ethanoldry ice bath. In total, we expect this amounted to no more than 2 min outside the anaerobic groundwater environment before freezing.

To determine the likely time frame of the response to oxygen exposure, gene transcript levels for key genes identified in the microarray experiments were quantified with qRT-PCR before oxygen exposure, immediately after oxidative stress $(10 \mathrm{~min}, 30 \mathrm{~min}$ and $60 \mathrm{~min}$ ), and after a longer duration of oxygen exposure (6h and $24 \mathrm{~h}$ ). To insure that a significant oxidative stress existed after $24 \mathrm{~h}$ (minimum 5\% headspace oxygen concentration (vol/vol\%)), cells were initially stressed with $10 \%$ oxygen during the mid-log growth phase. Immediately after oxygen injection, G. uraniireducens ceased growth and biomass concentrations decreased slightly over the 24-h period (Figure 3). The headspace oxygen concentration decreased with time for both viable and heat-sterilized cells as it reacted with media and biomolecules; however, the rate of decrease was

Table 3 Genes thought to be involved in chemotaxis and cell motility that were differentially expressed $(P<0.01)$ in $G$. uraniireducens cultures exposed to $5 \%$ oxygen

\begin{tabular}{|c|c|c|c|c|}
\hline Gene ID & Annotation & Mean $\log _{2}$ & Fold change & Gene name \\
\hline Gura1811 & Fimbrial assembly family protein & -1.08 & -2.12 & $\operatorname{pilN}$ \\
\hline Gura1812 & Pilus assembly protein & -1.01 & -2.01 & pilO \\
\hline Gura1813 & Hypothetical protein & -0.99 & -1.99 & - \\
\hline Gura4106 & Flagellar basal-body rod protein & -0.91 & -1.88 & $f \lg G$ \\
\hline Gura4207 & Flagellar hook-length control protein & -0.86 & -1.81 & fliK \\
\hline Gura4199 & Flagellar biosynthetic protein & -0.82 & -1.77 & fliP \\
\hline Gura4201 & Flagellar motor switch protein & -0.73 & -1.66 & fliN \\
\hline Gura3136 & Chemotaxis protein & -0.71 & -1.63 & cheY \\
\hline Gura4109 & Flagellar biosynthetic protein (ATPase) & -0.69 & -1.61 & flhG \\
\hline Gura4209 & Flagellar protein FliJ, putative & -0.66 & -1.58 & fli \\
\hline Gura4093 & Flagellin export facilitator protein & -0.61 & -1.52 & flis \\
\hline Gura2168 & Chemotaxis protein & -0.60 & -1.52 & cheW \\
\hline
\end{tabular}



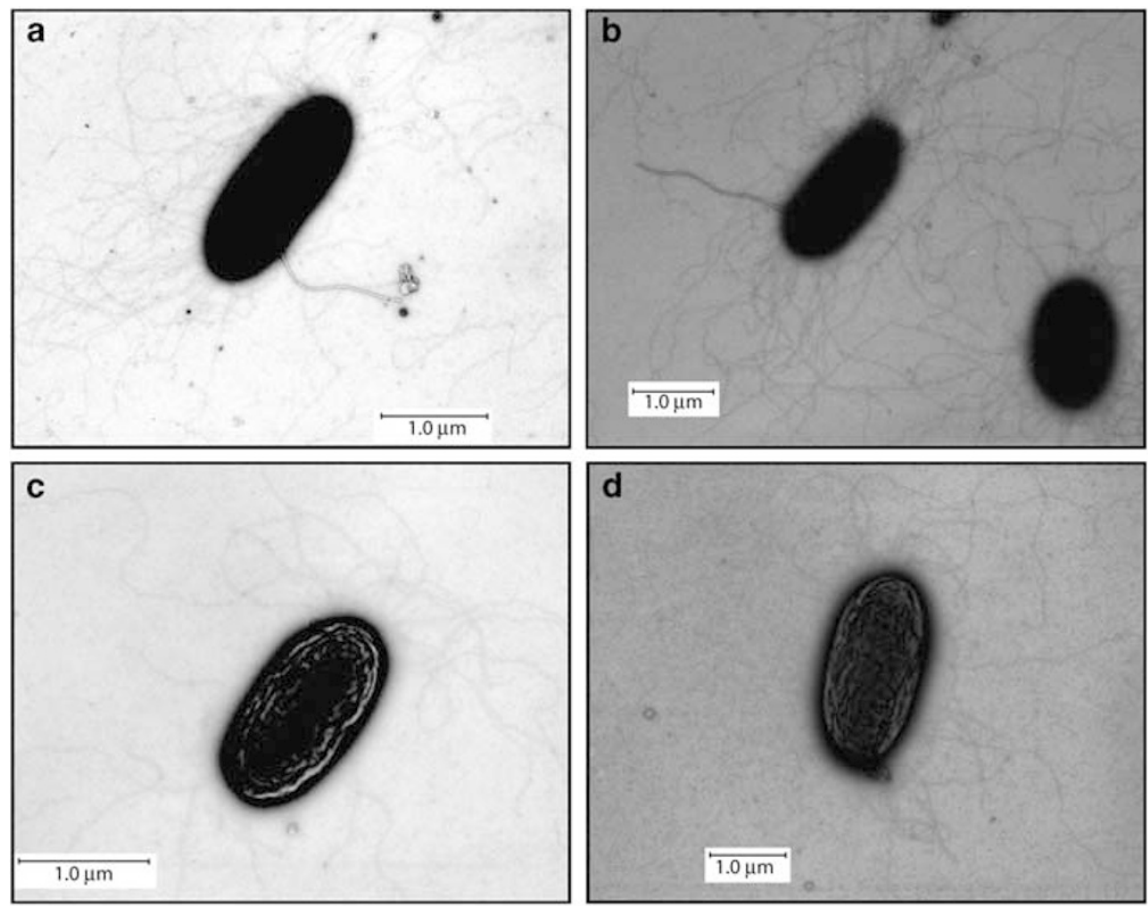

Figure 2 (a, b) Transmission electron microscope (TEM) images of G. uraniireducens grown anaerobically in fumarate as an electron acceptor, expressing pili in the majority of cells $(>95 \%)$ and flagella in some cells $(>10 \%)$ using a survey of 100 images on two different slides. (c, d) Cells grown anaerobically then stressed for $6 \mathrm{~h}$ under 10\% oxygen results in a reduced number of pili and no observed flagella in a survey of 100 images on two different slides.

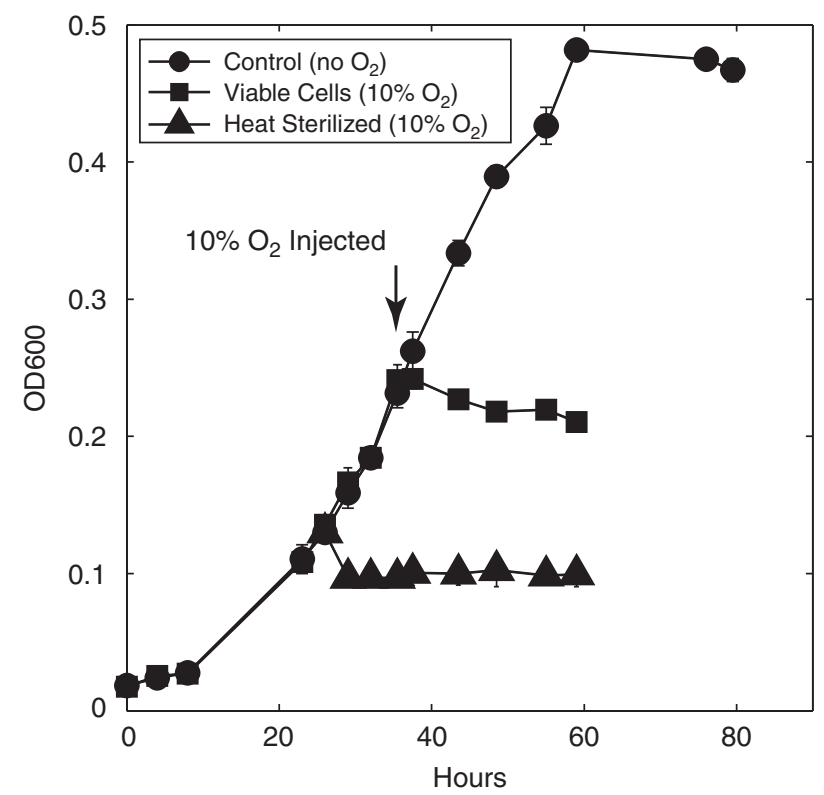

Figure 3 Optical density (absorbance at $600 \mathrm{~nm}$ ) of G. uraniireducens cultured in batch with acetate as the electron donor and fumarate as the electron acceptor under anoxic conditions (circles), during a 24 -h period of exposure to $10 \%$ oxygen (squares), and after cells were killed with heat during 24-h period exposure to $10 \%$ oxygen oxidative stress after heat sterilization (triangles).

more rapid in viable cells, suggesting limited oxygen uptake by $G$. uraniireducens (Figure 4a).

For genes with significant increases in expression upon exposure to oxygen, somewhere between
1 and $6 \mathrm{~h}$ was required for transcript levels to increase over twofold (Figures $4 \mathrm{c}$ and d). This response was fastest for the gene encoding the superoxide scavenger $\operatorname{Sod} A(\sim 1 \mathrm{~h})$ and longer for genes encoding energy metabolism and ion transport proteins such as CydA and MacA, which remained elevated for 6-24h after initial exposure (Figures 4c and d). In contrast, the levels of housekeeping genes $p r o C$ and $r p o B$ decreased slightly over this period as a result of cell death (Figure 4b). Significant differences $(P<0.05)$ in the number of transcripts for $c y d A, \operatorname{mac} A, d f_{X}$ and rbr in cells grown in batch and exposed to oxygen for $6 \mathrm{~h}$ was consistent with the microarray results from chemostat-grown cells exposed to oxygen for $8 \mathrm{~h}$. Although not statistically significant due to large biological replicate variability, transcript levels for $\operatorname{sod} A$ increased almost twofold after $1 \mathrm{~h}$ of oxygen exposure but decreased thereafter (Figure 4d).

Combined results from microarray and time course oxygen studies suggest that monitoring for genes encoding proteins involved in oxidative stress response, including SodA, Dfx and Rbr, may be technically challenging in the environment because fold changes are relatively small and short-lived, as compared with genes encoding CydA or MacA energy metabolism proteins, which have fold changes 5- to 10-fold larger, at levels that remain elevated $24 \mathrm{~h}$ after initial oxygen exposure (Table 2; Figures 4c and d). 

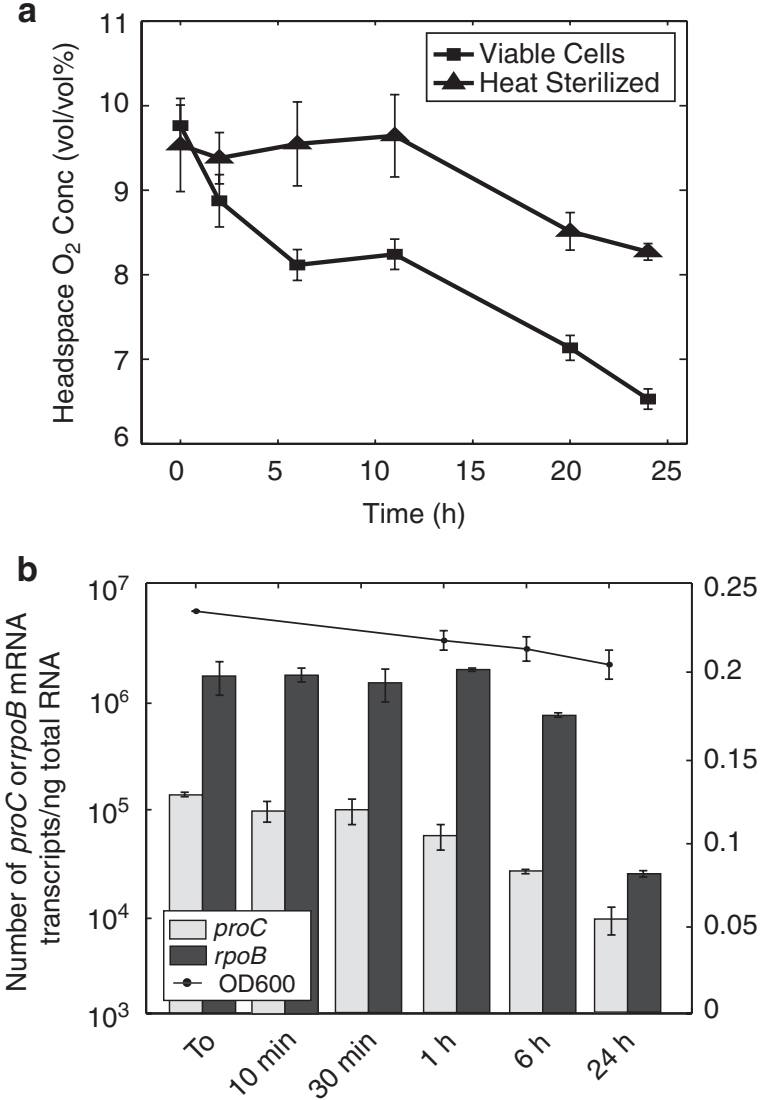

C

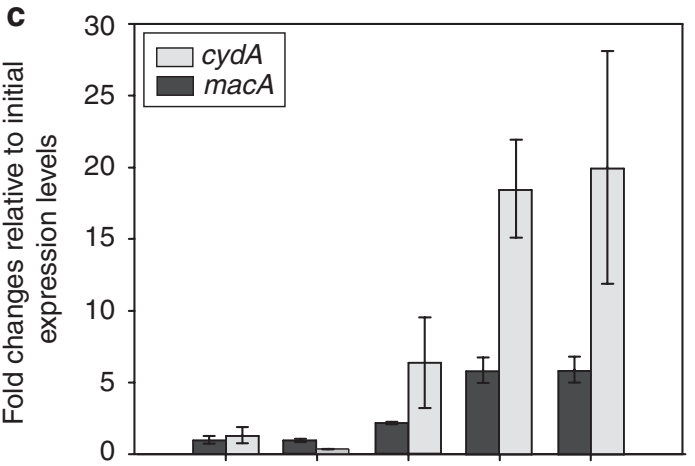

d

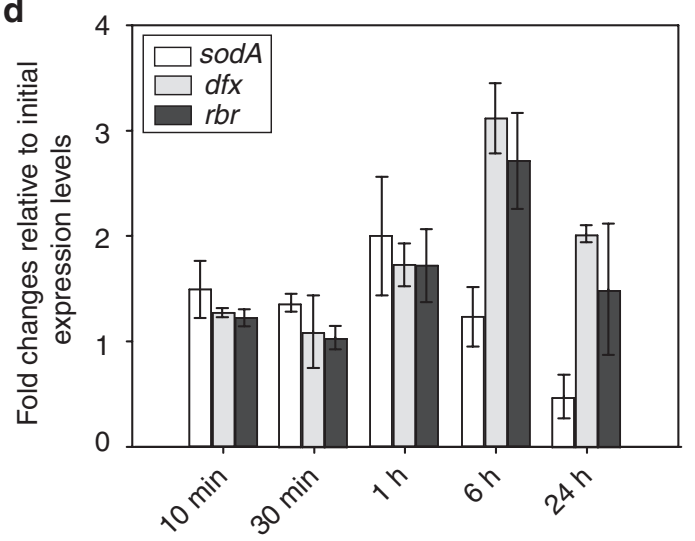

Figure 4 Headspace oxygen concentrations, biomass measurements and transcript abundance levels according to quantitative reverse transcription (qRT)-PCR for seven genes of interest for $G$. uraniireducens cells grown in batch and stressed over $24 \mathrm{~h}$ with $10 \%$ headspace vol/vol\% oxygen. (a) Headspace oxygen for viable and heat-sterilized cells. (b) The number of pyrroline-5-carboxylate reductase (proC), DNA-directed RNA polymerase beta subunit ( $r p o B)$ mRNA transcripts and biomass measurement (absorbance at $600 \mathrm{~nm}$ ). (c) Fold changes in the number of $c y d A$ and macA mRNA transcripts. (d) Fold changes in the number of $\operatorname{sod} A, d f x$ and $r b r$ mRNA transcripts. Headspace oxygen concentrations and OD600 results are reported as the mean (line) and standard deviation (error bars) of triplicate biological replicates, whereas expression results are reported as the mean (bars) and range (error bars) of two biological replicates and four technical replicates.

Impact of growth on Fe(III) on expression of oxidative stress genes

The cells in the studies described above were grown with fumarate as the electron acceptor, because it is necessary to use soluble electron acceptors for growth in chemostats and G. uraniireducens does not grow on Fe(III) citrate (Shelobolina et al., 2008), the only convenient form of soluble Fe(III) that can be supplied at high concentrations for chemostat growth. However, analysis of a previous wholegenome microarray comparison of $G$. sulfurreducens grown on fumarate and $\mathrm{Fe}(\mathrm{III})$ citrate suggested that cydA transcript levels were higher in Fe(III)-grown cells (Methe et al., 2005). Transcript abundance for both $\operatorname{cyd} A$ and $\operatorname{sod} A$ was also higher in $G$. sulfurreducens cells grown on Fe(III) as compared with growth on a current-harvesting electrode (Holmes et al., 2006).

To evaluate the effect of growth on Fe(III) might have on expression of oxidative stress genes compared with the impact that oxygen exposure alone might have on these genes, $G$. sulfurreducens was grown in chemostats with $\mathrm{Fe}$ (III) or fumarate as the electron acceptor and cells were exposed to oxygen. Transcript levels of $c y d A$ and $\operatorname{sod} A$ were 60 and 12-fold higher, respectively, when cells were grown anaerobically with Fe(III), and were five and eightfold higher in $\mathrm{Fe}(\mathrm{III})$-grown cells than cells grown on fumarate and exposed to $10 \%$ oxygen (Figure 5). Exposure of $\mathrm{Fe}$ (III)-grown cells to oxygen increased transcript abundance of $\operatorname{cydA}$ and $\operatorname{sod} A$ even further, from more than fourfold with $5 \%$ oxygen to greater than 90 -fold with $10 \%$ oxygen (Figure 5). These results demonstrate that growth on Fe(III) may result in relatively high transcript abundance of $\operatorname{cyd} A$ and $\operatorname{sod} A$ in the absence of oxygen and that the presence of oxygen in addition to growth on $\mathrm{Fe}(\mathrm{III})$ results in even greater increases in transcripts for these genes.

\section{Implications}

These results suggest that the initially surprising finding that the natural community of Geobacteraceae 


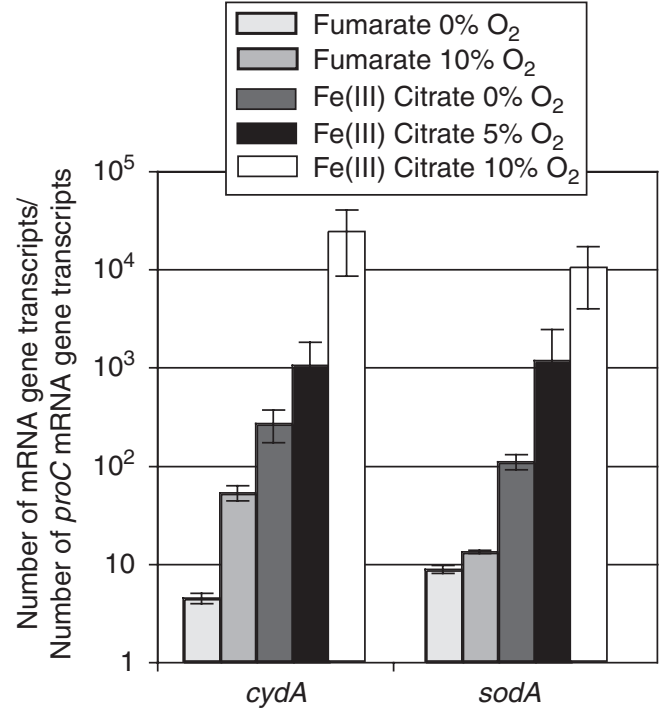

Figure 5 Relative expression of two oxidative stress genes, $\operatorname{cyd} A$ and $\operatorname{sod} A$, relative to proC, in G. sulfurreducens grown in continuous culture with either fumarate or Fe(III) citrate as the electron acceptor under different headspace oxygen concentrations. Results are reported as the mean of three biological replicates and three technical replicates.

involved in in situ uranium bioremediation at the Rifle site expressed $\operatorname{sod} A$ and $\operatorname{cyd} A$ under what would generally be considered anoxic environmental conditions, does not necessarily indicate that these cells were being exposed to oxygen in situ. Appreciable dissolved oxygen would not typically be expected in groundwater with substantial dissolved $\mathrm{Fe}(\mathrm{II})$ because $\mathrm{Fe}(\mathrm{II})$ rapidly reacts with oxygen at circumneutral pH (Lowson, 1982; Morgan and Lahav, 2007). Furthermore, relative expression levels for $c y d A$ and $\operatorname{sod} A$ observed in subsurface sediments during uranium biostimulation were between $10^{2}$ and $10^{3}$ during the plateau stage of growth. These ratios are similar to levels observed in G. sulfurreducens grown in chemostat culture in the presence of $\mathrm{Fe}(\mathrm{III})$ under anaerobic conditions (Figure 5). A potential alternative explanation was that the expression of the relatively high expression of $\operatorname{sod} A$ and $c y d A$ was an artifact of the cells being exposed to oxygen during collection. However, this explanation is not consistent with the time course experiments that clearly showed that long-term exposure to oxygen was required for significant increases in relative transcript levels. In addition, this would not explain the low levels of transcripts in $\operatorname{sod} A$ and $c y d A$ in the early stages of the field experiment or the decline in $c y d A$ in the latter stages of the bioremediation, which we believe to be related to in situ growth trends.

As the results from growth of $G$. sulfurreducens on $\mathrm{Fe}(\mathrm{III})$ demonstrate, factors other than the presence of oxygen may result in high expression of these genes. For example, previous whole-genome microarray studies of $G$. sulfurreducens found elevated expression of these genes during growth with Fe(III) citrate versus growth with fumarate or an electrode serving as the electron acceptor (Methe et al., 2005; Holmes et al., 2006). Furthermore, transcript abundance for a number of genes potentially associated with oxidative stress was also higher when $G$. uraniireducens was grown in sediments as compared with fumarate medium (Holmes et al., 2008). These considerations suggest that when diagnosing metabolic status of subsurface microorganisms through analysis of in situ gene transcript levels, it is important to interpret these in context with the appropriate environmental data and a complete understanding of all of the environmental factors that may influence the expression of the genes of interest.

\section{Acknowledgements}

This research was supported by the Office of Science Biological and Environmental Research (BER), US Department of Energy, Grant no. DE-FG02-07ER64377.

\section{References}

Anderson RT, Lovley DR. (1997). Ecology and biogeochemistry of in situ groundwater bioremediation. In: Jones (ed). Advances in Microbial Ecology, vol. 15. Plenum Press: New York, pp 289-350.

Anderson RT, Vrionis HA, Ortiz-Bernad I, Resch CT, Long $\mathrm{PE}$, Dayvault $\mathrm{R}$ et al. (2003). Stimulating the in situ activity of Geobacter species to remove uranium from the groundwater of a uranium-contaminated aquifer. Appl Environ Microbiol 69: 5884-5891.

Balch WE, Wolfe RS. (1979). Specificity and biological distribution of coenzyme M (2-mercaptoethanesulfonic acid). J Bacteriol 137: 256-263.

Beliaev AS, Klingeman DM, Klappenbach JA, Wu L, Romine MF, Tiedje JA et al. (2005). Global transcriptome analysis of Shewanella oneidensis MR-1 exposed to different terminal electron acceptors. J Bacteriol 187: 7138-7145.

Brumlik MJ, Voordouw G. (1989). Analysis of the transcriptional unit encoding the genes for rubredoxin $(R u b)$ and a putative rubredoxin oxidoreductase $(R b o)$ in Desulfovibrio vulgaris Hildenborough. J Bacteriol 171: 4996-5004.

Chin KJ, Esteve-Nunez A, Leang C, Lovley DR. (2004). Direct correlation between rates of anaerobic respiration and levels of mRNA for key respiratory genes in Geobacter sulfurreducens. Appl Environ Microbiol 70: 5183-5189.

Cypionka H. (2000). Oxygen respiration by Desulfovibrio species. Annu Rev Microbiol 54: 827-848.

Das A, Silaghi-Dumitrescu R, Ljungdahl LG, Kurtz DM. (2005). Cytochrome $b d$ oxidase, oxidative stress, and dioxygen tolerance of the strictly anaerobic bacterium Moorella thermoacetica. J Bacteriol 187: 2020-2029.

Edwards L, Kusel K, Drake H, Kostka JE. (2007). Electron flow in acidic subsurface sediments co-contaminated with nitrate and uranium. Geochim Cosmochim Acta 71: 643-654. 
Ellis DE, Lutz EJ, Odom JM, Buchanan RJ, Bartlett CL, Lee MD et al. (2000). Bioaugmentation for accelerated in situ anaerobic bioremediation. Environ Sci Technol 34: $2254-2260$.

Esteve-Nunez A, Rothermich M, Sharma M, Lovley D. (2005). Growth of Geobacter sulfurreducens under nutrient-limiting conditions in continuous culture. Environ Microbiol 7: 641-648.

Fareleira P, Santos BS, Antonio C, Moradas-Ferreira P, LeGall J, Xavier AV et al. (2003). Response of a strict anaerobe to oxygen: survival strategies in Desulfovibrio gigas. Microbiology 149: 1513-1522.

Finneran KT, Anderson RT, Nevin KP, Lovley DR. (2002). Potential for bioremediation of uranium-contaminated aquifers with microbial U(VI) reduction. Soil Sediment Contamin 11: 339-357.

Fleming JT, Sanseverino J, Sayler GS. (1993). Quantitative relationship between naphthalene catabolic genefrequency and expression in predicting $\mathrm{PAH}$ degradation in soils at town gas manufacturing sites. Environ Sci Technol 27: 1068-1074.

Hazen TC, Stahl DA. (2006). Using the stress response to monitor process control: pathways to more effective bioremediation. Curr Opin Biotechnol 17: 285-290.

He J, Sung Y, Krajmalnik-Brown R, Ritalahti KM, Loffler FE. (2005). Isolation and characterization of Dehalococcoides sp strain FL2, a trichloroethene (TCE)- and 1,2-dichloroethene-respiring anaerobe. Environ Microbiol 7: 1442-1450.

Heidelberg JF, Seshadri R, Haveman SA, Hemme CL, Paulsen IT, Kolonay JF et al. (2004). The genome sequence of the anaerobic, sulfate-reducing bacterium Desulfovibrio vulgaris Hildenborough. Nat Biotechnol 22: 554-559.

Holmes DE, Chaudhuri SK, Nevin KP, Mehta T, Methe BA, Liu A et al. (2006). Microarray and genetic analysis of electron transfer to electrodes in Geobacter sulfurreducens. Environ Microbiol 8: 1805-1815.

Holmes DE, Nevin KP, Lovley DR. (2004). In situ expression of nifD in Geobacteraceae in subsurface sediments. Appl Environ Microbiol 70: 7251-7259.

Holmes DE, Nevin KP, O’Neil RA, Ward JE, Adams LA, Woodard TL et al. (2005). Potential for quantifying expression of the Geobacteraceae citrate synthase gene to assess the activity of Geobacteraceae in the subsurface and on current-harvesting electrodes. Appl Environ Microbiol 71: 6870-6877.

Holmes DE, O'Neil RA, Chavan MA, N'Guessan LA, Vrionis HA, Perpetua LA et al. (2008). Transcriptome of Geobacter uraniireducens growing in uraniumcontaminated subsurface sediments. ISME J; e-pub ahead of print 9 October 2008; doi:10.1038/ismej. 2008.89.

Holmes DE, O’Neil RA, Vrionis HA, N'Guessan LA, OrtizBernad I, Larrahondo MJ et al. (2007). Subsurface clade of Geobacteraceae that predominates in a diversity of $\mathrm{Fe}(\mathrm{III})$-reducing subsurface environments. ISME J 1: 663-677.

Imlay JA. (2003). Pathways of oxidative damage. Annu Rev Microbiol 57: 395-418.

Imlay JA, Linn S. (1988). DNA damage and oxygen radical toxicity. Science 240: 1302-1309.

Istok JD, Senko JM, Krumholz LR, Watson D, Bogle MA, Peacock A et al. (2004). In situ bioreduction of technetium and uranium in a nitrate-contaminated aquifer. Environ Sci Technol 38: 468-475.
Jenney FE, Verhagen M, Cui XY, Adams MWW. (1999). Anaerobic microbes: oxygen detoxification without superoxide dismutase. Science 286: 306-309.

Johnson DR, Lee PKH, Holmes VF, Fortin AC, Alvarez-Cohen L. (2005). Transcriptional expression of the tceA gene in a Dehalococcoides-containing microbial enrichment. Appl Environ Microbiol 71: 7145-7151.

Keyer K, Imlay JA. (1996). Superoxide accelerates DNA damage by elevating free-iron levels. Proc Natl Acad Sci USA 93: 13635-13640.

Krekeler D, Teske A, Cypionka H. (1998). Strategies of sulfate-reducing bacteria to escape oxygen stress in a cyanobacterial mat. FEMS Microbiol Ecol 25: 89-96.

Kurtz DM. (2006). Avoiding high-valent iron intermediates: superoxide reductase and rubrerythrin. J Inorg Biochem 100: 679-693.

Lee PKH, Johnson DR, Holmes VF, He JZ, Alvarez-Cohen L. (2006). Reductive dehalogenase gene expression as a biomarker for physiological activity of Dehalococcoides spp. Appl Environ Microbiol 72: 6161-6168.

Lin WC, Coppi MV, Lovley DR. (2004). Geobacter sulfurreducens can grow with oxygen as a terminal electron acceptor. Appl Environ Microbiol 70: 2525-2528.

Lobo SAL, Melo AMP, Carita JN, Teixeira M, Saraiva LM. (2007). The anaerobe Desulfovibrio desulfuricans ATCC 27774 grows at nearly atmospheric oxygen levels. FEBS Lett 581: 433-436.

Lovley DR. (2003). Cleaning up with genomics: applying molecular biology to bioremediation. Nat Rev Microbiol 1: 35-44.

Lovley DR, Phillips EJP. (1986). Organic-matter mineralization with reduction of ferric iron in anaerobic sediments. Appl Environ Microbiol 51: 683-689.

Lowson RT. (1982). Aqueous oxidation of pyrite by molecular-oxygen. Chem Rev 82: 461-497.

Machado P, Felix R, Rodrigues R, Oliveira S, RodriguesPousada C. (2006). Characterization and expression analysis of the cytochrome $b d$ oxidase operon from Desulfovibrio gigas. Curr Microbiol 52: 274-281.

Methe BA, Nelson KE, Eisen JA, Paulsen IT, Nelson W, Heidelberg JF et al. (2003). Genome of Geobacter sulfurreducens: metal reduction in subsurface environments. Science 302: 1967-1969.

Methe BA, Webster J, Nevin K, Butler J, Lovley DR. (2005). DNA microarray analysis of nitrogen fixation and Fe(III) reduction in Geobacter sulfurreducens. Appl Environ Microbiol 71: 2530-2538.

Morgan B, Lahav O. (2007). The effect of $\mathrm{pH}$ on the kinetics of spontaneous $\mathrm{Fe}(\mathrm{II})$ oxidation by O-2 in aqueous solution-basic principles and a simple heuristic description. Chemosphere 68: 2080-2084.

Moser DP, Nealson KH. (1996). Growth of the facultative anaerobe Shewanella putrefaciens by elemental sulfur reduction. Appl Environ Microbiol 62: 2100-2105.

Mukhopadhyay A, Redding AM, Joachimiak MP, Arkin A, Borglin SC, Dehal PS et al. (2007). Cell-wide responses to low-oxygen exposure in Desulfovibrio vulgaris Hildenborough. J Bacteriol 189: 5996-6010.

North NN, Dollhopf SL, Petrie L, Istok JD, Balkwill DL, Kostka JE. (2004). Change in bacterial community structure during in situ biostimulation of subsurface sediment cocontaminated with uranium and nitrate. Appl Environ Microbiol 70: 4911-4920.

O’Neil RA, Holmes DE, Coppi MV, Adams LA, Larrahondo MJ, Ward JE et al. (2008). Gene transcript analysis of assimilatory iron limitation in Geobacteraceae during 
groundwater bioremediation. Environ Microbiol 10: 1218-1230.

Parro V, Moreno-Paz M, Gonzalez-Toril E. (2007). Analysis of environmental transcriptomes by DNA microarrays. Environ Microbiol 9: 453-464.

Postier B, DiDonato RJ, Nevin KP, Liu A, Frank B, Lovley D et al. (2008). Benefits of in-situ synthesized microarrays for analysis of gene expression in understudied microorganisms. J Microbiol Methods 74: 26-32.

Rahm BG, Richardson RE. (2008). Correlation of respiratory gene expression levels and pseudo-steady-state PCE respiration rates in Dehalococcoides ethenogenes. Environ Sci Technol 42: 416-421.

Röling WFM, van Verseveld HW. (2002). Natural attenuation: what does the subsurface have in store? Biodegradation 13: 53-64.

Saleh-Lakha S, Miller M, Campbell RG, Schneider K, Elahimanesh P, Hart MM et al. (2005). Microbial gene expression in soil: methods, applications and challenges. J Microbiol Methods 63: 1-19.
Shelobolina ES, Vrionis HA, Findlay RH, Lovley DR. (2008). Geobacter uraniireducens sp. nov., isolated from subsurface sediment undergoing uranium bioremediation. Int $J$ Syst Evol Microbiol 58: 1075-1078.

Silva G, Oliveira S, Gomes CM, Pacheco I, Liu MY, Xavier AV et al. (1999). Desulfovibrio gigas neelaredoxin-a novel superoxide dismutase integrated in a putative oxygen sensory operon of an anaerobe. Eur J Biochem 259: $235-243$.

Smyth GK, Michaud J, Scott HS. (2005). Use of withinarray replicate spots for assessing differential expression in microarray experiments. Bioinformatics 21: 2067-2075.

Smyth GK, Speed T. (2003). Normalization of cDNA microarray data. Methods 31: 265-273.

Voordouw JK, Voordouw G. (1998). Deletion of the rbo gene increases the oxygen sensitivity of the sulfatereducing bacterium Desulfovibrio vulgaris Hildenborough. Appl Environ Microbiol 64: 2882-2887.

Supplementary Information accompanies the paper on The ISME Journal website (http://www.nature.com/ismej) 